\title{
Association Between Second Hand Smoke (SHS) Exposure In Pregnant Women And Their Socioeconomic Status (SES) And Its Interaction With Age: A Cross-Sectional Study In Urban Areas
}

\section{Zhou Wensu}

Central South University

Zhu Xidi

Central South University

Hu Zhao

Central South University

\section{Li Shaojie}

Central South University

\section{Zheng Baohua}

Central South University

\section{Yu Yunhan}

Central South University

Xu Huilan

Central South University

Xiong Xiyue ( $\nabla$ xiong_fybj@163.com )

Hunan Provincial Maternal and Child Health Care Hospital

\section{Research Article}

Keywords: pregnancy, socioeconomic status, second-hand smoke, cross-sectional study, China

Posted Date: December 16th, 2021

DOI: https://doi.org/10.21203/rs.3.rs-1105976/v1

License: (9) This work is licensed under a Creative Commons Attribution 4.0 International License. Read Full License 


\section{Abstract}

Background: The high rate of second hand smoke (SHS) exposure puts pregnant women at risk of various harms and identify relevant influence factors are vital for primary prevention. The study aimed to explore the effect of individual socioeconomic status (SES) on exposure to SHS exposure among pregnant women.

Methods: A total of 678 non-smoker pregnant women from 14 communities of Hengyang city, Hunan province of China were recruited in this survey. A self-designed structural questionnaire was used to collect variables. Exposure to SHS was defined as self-reported smoking habit of spouse/partner. The individual SES consisted of martial status, educational attainment, employment and per-capita monthly income.

Results: There were 238 (35.1\%) participants suffered from SHS exposure during pregnancy. After adjusted for confounding variables, compared to the pregnant women who were employed, others were unemployed were more likely to suffer from SHS exposure (OR=1.697; 95\% Cl: 1.102-2.614). Similarly, those women who had high school or technical secondary school education level were associated with SHS exposure compared with college or above education attachment (OR: 1.577, 95\%Cl: 1.020-2.437). The interaction effects between age and junior middle school or below educational attainment (OR: $1.131,95 \% \mathrm{Cl}: 1.015-1.261)$, unstable marriage (OR: 1.380, 95\%Cl: 1.075-1.772) on SHS exposure was detected.

Conclusion: Exposure to SHS was very common among pregnant women. Those pregnant women of low level of SES should considered as key population to implement public health intervention. Pregnant women of unstable martial status with older age were more likely to SHS exposure.

\section{Background}

The most well-known unhealthy habits -smoking is common among adults especially male, in most countries, overall, there were $50 \%$ and $35 \%$ of male had smoking habit in developing and developed countries, respectively [1]. Namely, there would be a big number of female suffered from second-hand smoke (SHS) exposure, especially those women who experiencing pregnancy. Over the past few decades, lots of epidemiological studies also suggested that pregnant women were exposure to second-hand smoke (SHS) sources from their partner was very common during pregnancy, although they were nonsmokers [2-4]. Previous studies have shown that exposure to SHS is more serious than active smoking [5-7] because it measured as 3 to 4 times more damaging per gram of particulate matter than smoke directly inhaled by the smoker [8]. Increasing number of studies indicated as exposure to SHS that affected almost every phase of adverse pregnancy outcomes, such as depression disorder, low level of health-related quality of life, preterm labor, rupture of membranes, fetal weight loss, and so on $[6,9,10]$.

Socioeconomic status (SES) which considered as a construct, mainly involved such factors like educational attainment, occupational status, income and wealth [11]. SES represented a person's 
capacity of resources and it was associated with health behavior, attitude and outcomes [12]. Previous studies indicated that individual characteristic of socioeconomic status (SES) not only affected active smoking behavior but also links with SHS exposure [13-15]. Whereas, whether or not SES affected SHS exposure during pregnancy was debatable. For instance, Madureira et al, reported that duration of educational attainment over 13 years was a protective factor for reducing environmental tobacco exposure during pregnancy [15], which was similar to other studies $[2,16,17]$. The probability of daily SHS exposure in home was negative associated with household income and family wealth of pregnant women $[2,16]$. Yet, despite researcher found occupation was significantly associated with active smoking and SHS exposure during pregnancy [18, 19], Reece and colleagues did not identified this association [2]. Morever, many of researchers have found marital functioning is consequential for health and considered it as a positive indicator linked to reduce harmful exposure and engage health behavior [20], but statistical significance was not reported in two studies focused on the links between martial status and SHS exposure during pregnancy [21,22]. Besides, the magnitude of SHS exposure and its association with SES could vary by regions, as previous study showed huge heterogeneity in cultural background, tobacco use and attitude across countries [4,21]. Which means the conclusions drawn from different countries may not reflect the same situation in other country. Some conclusions are expected to be updated when sufficient evidences from new research conducted in populations becomes available.

In additional, pregnant women's age was also considered as another indicator to predict the SHS exposure during pregnancy and it was positive associated with SHS exposure $[21,23,24]$. The accumulation hypothesis showed the level of SES-based health advantage progressively decline as age [25]. That might suggest an age interaction with SES. Meanwhile, age is an important risk factor for pregnant women because the older the women, the higher risk of death or injury fo fetus. Thus, the effect of age and SES on SHS exposure is of particular interest, but present literature is not clear on its connection.

In summary, the current study relied on a community-based sample to reflect the association between individual SES and SHS exposure among pregnant women as well as explored the interaction between age and SES on SHS exposure. It of great importance to greatly facilitate the design and implementation of effective public prevention programs and policies.

\section{Method}

\section{Study design and participants}

Data was derided from a cross-sectional study based on community investigation conducted in Hengyang city, Hunan province of China during July to September 2019. The Hengyang city is a typical industrial city located in central China. The survey use a stratified random sampling strategy, with districts as the primary sampling unit. First, 5 streets were randomly selected from 5 districts of Hengyang city. Then, communities were selected randomly based on a community and a streets at a ratio of 3 : 1. Finally, 4 communities of Zhengxiang street, 3 communities of Qingshan street, 3 communities of 
Baishazhou street, 2 communities of Guangdong road street and 2 communities of Zhurong street with a total of 819 pregnant women in the third trimeste were recruited in this study. Inclusion criterion: 1) aged over 18 years; 2) volunteer to the project; 3 ) the participant has came to pregnancy registration in the community health centers and living in the community for more than 6 months; 4) non-smokers during pregnancy; 5) living with spouse/partner during pregnancy. Out of the recruited women, 6 participants were excluded given the missing information in smoking habits and exposure, 135 participants were excluded due to not met the inclusion criterion. A total of 678 pregnant women at 3rd trimester were included in analysis. All of the participants were asked to receive an interview for twenty minutes and completed a structured questionnaire to collect information of them. Meanwhile, the participants were signed informed consent. The study has been approved by the Ethics Committee of the Xiangya school of Public Health, Central South University on 15, July, 2019 (XYGW-2019-056). The flow chart of this study is present in figure 1 .

\section{Assessment Of Exposure To Passive Shs Exposure}

According to the definition in the Global Adult Tobacco Survey 2010, secondhand smoke exposure (SHS), all of pregnant women were asked to response a question "Whether your spouse/partner smoking in home at least 1 day per week while you're pregnant ?" assessed by a specific questionnaire. Those who responded "yes" and "always" were considered to be exposed to secondhand smoke in home during pregnancy.

\section{Assessment Of Individual Socioeconomic Status (Ses)}

In the light of the social age concept, the individual socioeconomic status was measured by asking individual educational level, employment status, marital status and per-capita monthly income. Among them, educational level was categorized as junior middle school or below, high school or technical secondary school and college or above, employment status was categorized as yes and no, marital status was classified as single/divorced or married. Besides, person income per month was divided into three groups including $\leq 3000 \mathrm{RMB}, 3001-7999 \mathrm{RMB}$ and $\geq 8000 \mathrm{RMB}$.

\section{Covariates}

Several variables were considered as covariates put into analysis involved: age and the household registration status (hukou) (rural areas and urban areas). Behavioral lifestyle of the participants included: smoking habit (never and former), exercising at the present (yes and no) and drinking at the present (yes and no). Family related factors included: educational attainment of spouse/partner (junior middle school or below, high school or technical secondary school and college or above), drinking habit of spouse/partner in the last year (yes and no) and living with aunt/uncle after get married (yes and no). 


\section{Statistics Analysis}

The characteristics of the participants were presented as means and standard deviations for continue variables met normal distribution, or median and inter-quartile range for continue variables not met normal distribution, or as number and percentages for categorized variables. The difference of exposure to passive SHS according to demographic characteristic, SES and family factors was examined using the chi-square test. The difference of age of SHS exposure was analyzed using non-parametric KruskalWallis test since the age was not confirmed as normal distribution. The binary logistic regression analysis with enter method was applied to explore the association between SES and exposure to passive SHS in the 3rd trimester among pregnant women after controlling age, ethnic, the household registration status, smoking habit, exercising and drinking at the present, employment of spouse/partner, educational attainment of spouse/partner, drinking habit of spouse/partner in the last year, living with aunt/uncle after get married, regular antenatal examination and complications of pregnancy. The model 1 was multivariate logistic regression model only included educational attainment, martial status, employment and per-capita monthly income. The model 2 was multivariate logistic regression model after adjusted for covariates. Lastly, we conducted a product term into the multivariate logistic regression model to examine the effects of age and SES on SHS exposure. Associations were presented as crude and adjusted odds ratio (OR) with $95 \%$ confidence intervals $(95 \% \mathrm{Cl}$ ). All of analyses were conducted using the $\mathrm{R}$ v4.0.5. A pvalue $<0.05$ was considered statistically significant.

\section{Results}

\section{Demographic of study sample}

Table 1 shows the individual demographic and the difference comparison of respondents. Overall, of the 678 pregnant women based on this community-base survey, 35.1\% (238) of them had SHS exposure in home. The mean age of the participants was 29.1 years $(S D=4.6) .97 .8 \%$ of them were Han ethnic with urban household registration status (73.2\%). $95.4 \%$ of the women were married and living with partner/spouse together and employed (74.9\%). The proportion of the participants with were junior middle school or below, high school or technical secondary school and college or above educational attainment were $19.5 \%, 23.7 \%$ and $56.8 \%$, respectively. There were $8.8 \%, 71.1 \%$ and $20.1 \%$ of them with person income per month less than $3000 \mathrm{RMB}$, between 3001-7999 RMB and more than $8000 \mathrm{RMB}$, respectively. Only $4.3 \%$ and 9.7 of them reported they had smoking habit before pregnancy and drinking at the present. Regarded to the characteristic of spouse/partner, over half of spouse/partner had employed and college or above educational attainment as well as drinking habit in the last year. There were $64.0 \%$ of the participants living with aunt/uncle after get married. The percentages of regular antenatal examination and complication of pregnancy were $91.6 \%$ and $10.5 \%$, respectively. 
Table 1

Characteristics of the pregnant women at 3rd trimester according to exposure to SHS

\begin{tabular}{|c|c|c|c|c|}
\hline Characteristic & $\begin{array}{l}\text { Total } \\
n=678\end{array}$ & $\begin{array}{l}\text { Never } \\
\text { exposure to SHS } \\
\text { during pregnancy } \\
n=440\end{array}$ & $\begin{array}{l}\text { Current exposure to } \\
\text { SHS during pregnancy } \\
\mathrm{n}=238\end{array}$ & $\stackrel{p}{\text { Value }}$ \\
\hline Age & $\begin{array}{l}29.1 \\
(4.60)\end{array}$ & $29.2(4.67)$ & $28.8(4.48)$ & 0.310 \\
\hline \multicolumn{5}{|l|}{ Ethic } \\
\hline Han & $\begin{array}{l}663 \\
(97.8)\end{array}$ & $427(97.0)$ & $236(99.2)$ & 0.074 \\
\hline Minority & $\begin{array}{l}15.0 \\
(2.2)\end{array}$ & $13.0(3.0)$ & $2.00(0.8)$ & \\
\hline \multicolumn{5}{|l|}{$\begin{array}{l}\text { The household registration } \\
\text { status(hukou) }\end{array}$} \\
\hline Rural areas & $\begin{array}{l}182 \\
(26.8)\end{array}$ & $115(26.1)$ & $67.0(28.2)$ & 0.572 \\
\hline Urban areas & $\begin{array}{l}496 \\
(73.2)\end{array}$ & 325 (73.9) & $171(71.8)$ & \\
\hline \multicolumn{5}{|l|}{ Individual SES } \\
\hline \multicolumn{5}{|l|}{ Marital Status } \\
\hline Married and living together & $\begin{array}{l}647 \\
(95.4)\end{array}$ & $417(94.8)$ & $230(96.6)$ & 0.267 \\
\hline $\begin{array}{l}\text { Divorced but living } \\
\text { together/Cohabiting } \\
\text { relationship }\end{array}$ & $\begin{array}{l}31.0 \\
(4.6)\end{array}$ & $23.0(5.2)$ & $8.00(3.4)$ & \\
\hline \multicolumn{5}{|l|}{ Employment } \\
\hline Yes & $\begin{array}{l}508 \\
(74.9)\end{array}$ & $346(78.6)$ & $162(68.1)$ & 0.002 \\
\hline No & $\begin{array}{l}170 \\
(25.1)\end{array}$ & $94.0(21.4)$ & $76.0(31.9)$ & \\
\hline \multicolumn{5}{|l|}{ Educational attainment } \\
\hline $\begin{array}{l}\text { Junior middle school or } \\
\text { below }\end{array}$ & $\begin{array}{l}132 \\
(19.5)\end{array}$ & $82.0(18.6)$ & $50.0(21.0)$ & 0.129 \\
\hline $\begin{array}{l}\text { High school or technical } \\
\text { secondary school }\end{array}$ & $\begin{array}{l}161 \\
(23.7)\end{array}$ & $96.0(21.8)$ & $65.0(27.3)$ & \\
\hline College or above & $\begin{array}{l}385 \\
(56.8)\end{array}$ & $262(59.5)$ & $123(51.7)$ & \\
\hline
\end{tabular}




\begin{tabular}{|c|c|c|c|c|}
\hline Characteristic & $\begin{array}{l}\text { Total } \\
\mathrm{n}=678\end{array}$ & $\begin{array}{l}\text { Never } \\
\text { exposure to SHS } \\
\text { during pregnancy } \\
n=440\end{array}$ & $\begin{array}{l}\text { Current exposure to } \\
\text { SHS during pregnancy } \\
\mathrm{n}=238\end{array}$ & Value \\
\hline \multicolumn{5}{|l|}{$\begin{array}{l}\text { Per-capita monthly } \\
\text { income,RMB }\end{array}$} \\
\hline$\leq 3000$ & $\begin{array}{l}60.0 \\
(8.8)\end{array}$ & $40.0(9.1)$ & $20.0(8.4)$ & 0.878 \\
\hline 3001-7999 & $\begin{array}{l}482 \\
(71.1)\end{array}$ & $314(71.4)$ & $168(70.6)$ & \\
\hline$\geq 8000$ & $\begin{array}{l}136 \\
(20.1)\end{array}$ & $86.0(19.5)$ & $50.0(21.0)$ & \\
\hline \multicolumn{5}{|l|}{ Smoking habit } \\
\hline Never & $\begin{array}{l}649 \\
(95.7)\end{array}$ & $419(95.2)$ & $230(96.6)$ & 0.386 \\
\hline Former & $\begin{array}{l}29.0 \\
(4.3)\end{array}$ & $21.0(4.8)$ & $8.00(3.4)$ & \\
\hline \multicolumn{5}{|l|}{ Exercising at the present } \\
\hline Yes & $\begin{array}{l}620 \\
(91.4)\end{array}$ & 399 (90.7) & 221 (92.9) & 0.334 \\
\hline No & $\begin{array}{l}58.0 \\
(8.6)\end{array}$ & $41.0(9.3)$ & $17.0(7.1)$ & \\
\hline \multicolumn{5}{|l|}{ Drinking at the present } \\
\hline No & $\begin{array}{l}612 \\
(90.3)\end{array}$ & 408 (92.7) & $204(85.7)$ & 0.003 \\
\hline Yes & $\begin{array}{l}66.0 \\
(9.7)\end{array}$ & $32.0(7.3)$ & $34.0(14.3)$ & \\
\hline \multicolumn{5}{|l|}{$\begin{array}{l}\text { Educational attainment of } \\
\text { spouse/partner }\end{array}$} \\
\hline $\begin{array}{l}\text { Junior middle school or } \\
\text { below }\end{array}$ & $\begin{array}{l}94.0 \\
(13.9)\end{array}$ & $66.0(15.0)$ & $28.0(11.8)$ & 0.218 \\
\hline $\begin{array}{l}\text { High school or technical } \\
\text { secondary school }\end{array}$ & $\begin{array}{l}172 \\
(25.4)\end{array}$ & $117(26.6)$ & $55.0(23.1)$ & \\
\hline College or above & $\begin{array}{l}412 \\
(60.8)\end{array}$ & $257(58.4)$ & $155(65.1)$ & \\
\hline $\begin{array}{l}\text { Employment of } \\
\text { spouse/partner }\end{array}$ & & & & \\
\hline
\end{tabular}




\begin{tabular}{|c|c|c|c|c|}
\hline Characteristic & $\begin{array}{l}\text { Total } \\
n=678\end{array}$ & $\begin{array}{l}\text { Never } \\
\text { exposure to SHS } \\
\text { during pregnancy } \\
n=440\end{array}$ & $\begin{array}{l}\text { Current exposure to } \\
\text { SHS during pregnancy } \\
\mathrm{n}=238\end{array}$ & $\stackrel{p}{\text { Value }}$ \\
\hline Yes & $\begin{array}{l}665 \\
(98.1)\end{array}$ & $431(98.0)$ & $234(98.3)$ & 0.741 \\
\hline No & $\begin{array}{l}13.0 \\
(1.9)\end{array}$ & $9.00(2.0)$ & $4.00(1.7)$ & \\
\hline \multicolumn{5}{|c|}{$\begin{array}{l}\text { Drinking habit of } \\
\text { spouse/partner in the last } \\
\text { year }\end{array}$} \\
\hline No & $\begin{array}{l}252 \\
(37.2)\end{array}$ & $119(27.0)$ & $133(55.9)$ & $<0.001$ \\
\hline Yes & $\begin{array}{l}426 \\
(62.8)\end{array}$ & $321(73.0)$ & $105(44.1)$ & \\
\hline \multicolumn{5}{|c|}{$\begin{array}{l}\text { Living with aunt/uncle after } \\
\text { get married }\end{array}$} \\
\hline No & $\begin{array}{l}244 \\
(36.0)\end{array}$ & $177(40.2)$ & $67.0(28.2)$ & 0.002 \\
\hline Yes & $\begin{array}{l}434 \\
(64.0)\end{array}$ & $263(59.8)$ & $171(71.8)$ & \\
\hline \multicolumn{5}{|c|}{$\begin{array}{l}\text { Regular antenatal } \\
\text { examination }\end{array}$} \\
\hline Yes & $\begin{array}{l}621 \\
(91.6)\end{array}$ & $392(89.1)$ & $229(96.2)$ & 0.001 \\
\hline No & $\begin{array}{l}57.0 \\
(8.4)\end{array}$ & $48.0(10.9)$ & $9.00(3.8)$ & \\
\hline \multicolumn{5}{|c|}{ Complications of pregnancy } \\
\hline No & $\begin{array}{l}607 \\
(89.5)\end{array}$ & $391(88.9)$ & $216(90.8)$ & 0.442 \\
\hline Yes & $\begin{array}{l}71.0 \\
(10.5)\end{array}$ & $49.0(11.1)$ & $22.0(9.2)$ & \\
\hline
\end{tabular}

After analyzed the difference under different demographic characteristic conditions, we observed significantly differed in employment $(p=0.002)$, drinking at the present $(p=0.003)$, drinking habit of spouse/partner in the last year $(p<0.001)$, living with aunt/uncle after get married $(p=0.002)$ and regular antenatal examination $(\mathrm{p}=0.001)$ (Table 1$)$.

\section{The association between SES and SHS exposure among pregnant women at 3rd trimester}


We used binary logistic regression analysis to explore the association between SES and SHS exposure among those women. Model 1 and 2 are summarized in Table 2. Model 1 was the base model that only educational attainment, employment, martial status and person income per month involved, which showed the participants was unemployed (OR:1.658, 95\% Cl: 1.126-2.441) was more likely to exposure to SHS in home. After controlling the covariates included age, ethnic, the household registration status, smoking habit, exercising and drinking at the present, employment of spouse/partner, educational attainment of spouse/partner, drinking habit of spouse/partner in the last year, living with aunt/uncle after get married, regular antenatal examination and complications of pregnancy, Model 2 showed those unemployed women (OR:1.697, 95\%Cl: 1.102-2.614) had increased risk for exposure to SHS than employed women. Participants of high school or technical secondary school educational attainment were more likely to exposure to SHS than these women of college or above educational attainment (OR:1.577, 95\% Cl: 1.020-2.437).

\section{Table 2 Binary logistic regression models for the association between SES and SHS among pregnant women at 3rd trimester}




\begin{tabular}{|c|c|c|c|c|}
\hline & $\begin{array}{l}\text { Model } \\
1\end{array}$ & $\mathrm{OR}(95 \% \mathrm{Cl})$ & $\begin{array}{l}\text { Model } \\
2\end{array}$ & $\mathrm{OR}(95 \% \mathrm{Cl})$ \\
\hline \multicolumn{5}{|l|}{ Marital Status } \\
\hline $\begin{array}{l}\text { Divorced but living together/Cohabiting } \\
\text { relationship }\end{array}$ & 0.537 & $\begin{array}{l}0.232- \\
1.244\end{array}$ & 0.562 & $\begin{array}{l}0.227- \\
1.390\end{array}$ \\
\hline Married and living together & 1 & & 1 & \\
\hline \multicolumn{5}{|l|}{ Employment } \\
\hline No & 1.658 & $\begin{array}{l}1.126- \\
2.441\end{array}$ & 1.697 & $\begin{array}{l}1.102- \\
2.614\end{array}$ \\
\hline Yes & 1 & & 1 & \\
\hline \multicolumn{5}{|l|}{ Educational attainment } \\
\hline Junior middle school or below & 1.161 & $\begin{array}{l}0.739- \\
1.824\end{array}$ & 1.311 & $\begin{array}{l}0.797- \\
2.157\end{array}$ \\
\hline High school or technical secondary school & 1.317 & $\begin{array}{l}0.879- \\
1.972\end{array}$ & 1.577 & $\begin{array}{l}1.020- \\
2.437\end{array}$ \\
\hline College or above & 1 & & 1 & \\
\hline \multicolumn{5}{|l|}{ Person income per month, RMB } \\
\hline$\leq 3000$ & 0.759 & $\begin{array}{l}0.392- \\
1.469\end{array}$ & 0.896 & $\begin{array}{l}0.442- \\
1.816\end{array}$ \\
\hline $3001-7999$ & 0.864 & $\begin{array}{l}0.576- \\
1.295\end{array}$ & 0.955 & $\begin{array}{l}0.619- \\
1.472\end{array}$ \\
\hline$\geq 8000$ & 1 & & 1 & \\
\hline
\end{tabular}

Model 1: included marital status, employment, educational attainment and person income per month.

Model 2: model 1+adjusted for age,ethnic, the household registration status , smoking habit, exercising and drinking at the present, employment of spouse/partner, educational attainment of spouse/partner, drinking habit of spouse/partner in the last year, living with aunt/uncle after get married, regular antenatal examination and complications of pregnancy.

\section{The interaction effect between SES and age on SHS exposure}

Table 3 indicated the interaction effect between age and SES on SHS among pregnant women at 3rd trimester. In Model 2, we observed after controlling for covariates, those women of divorced but living together/cohabiting relationship (OR:1.380, 95\% Cl: 1.075-1.772) had increased risk for exposure to SHS with age. The participants of junior middle school or below educational attainment were more likely to exposure to SHS with age (OR:1.131, 95\%Cl: 1.015-1.261). 
Table 3

The interaction effect between age and SES on SHS among pregnant women at 3rd trimester

$\begin{array}{llll}\text { Model } 1 & \text { OR }(95 \% \mathrm{Cl}) & \text { Model } 2 & \text { OR }(95 \% \mathrm{Cl})\end{array}$

Marital Status

Divorced but living together/Cohabiting relationship*age

1.301

$1.055-1.605$

1.380

$1.075-1.772$

Married and living together*age

1

1

Employment

No*age

0.985

$0.904-1.073$

1.012

$0.920-1.114$

Yes*age

1

1

Educational attainment

Junior middle school or below*age

1.097

$0.994-1.211$

1.131

1.015-1.261

High school or technical secondary school*age

$\begin{array}{llll}1.073 & 0.991-1.163 & 1.074 & 0.978-1.180\end{array}$

College or above*age

1

1

Person income per month, $\mathrm{RMB}$

$\leq 3000 *$ age

0.924

$0.812-1.052$

0.884

$0.754-1.037$

$3001-7999 * a g e$

0.927

$0.874-0.983$

0.927

$0.833-1.031$

$\geq 8000 *$ age

1

1

Model 1: included marital status, employment, educational attainment and person income per month.

Model 2: model 1+adjusted for age,ethnic, the household registration status, smoking habit, exercising and drinking at the present, employment of spouse/partner, educational attainment of spouse/partner, drinking habit of spouse/partner in the last year, living with aunt/uncle after get married, regular antenatal examination and complications of pregnancy.

\section{Discussion}

To the best of our knowledge, there was a dearth of studies on the relationship between individual SES and SHS exposure in home among pregnant women at 3rd trimester in China. The study not only provided insight in the status of SHS exposure but also examined this relationship with SES.

Unemployment and high school or technical secondary school educational attainment were significant effects on SHS exposure. In present study, we found that unstable marriage (cohabiting relationship) and junior middle school or below educational attainment were associated with elevated risk of SHS exposure enhanced by age. 
The finding showed the current SHS exposure prevalence from this study was $35.1 \%$ which was lower than the previous national-level study from 2013 (47.2\%) [26]. The prevalence of SHS exposure in this paper also lower than prior population-based studies conducted in Henan Province and Sichuan Province reported, there were $60-70 \%$ of pregnant women experienced SHS exposure overall and $75.1 \%$ of nonsmoking pregnant women suffered from chronic SHS exposure of respective spouses, respectively $[4,27]$. As previous study reported, the higher probabilities of SHS exposure was occurred in low and mid-income countries [2]. It could be perceived that the rate of SHS exposure among pregnant women varied from regions, with some locations having a high level of exposure but other regions were not. China is a most country of tobacco production and consumer in the world, about $47.2 \%$ of male had smoking habit in a investigation conducted in 2013 [26]. Tobacco plays an very important role in China economics and culture. The government has calls up adults away from tobacco, there were still great number of male had smoking habit in China. Overall, smoking was a widely acceptable behavior in China, although SHS has became a major public health problem and has caused heavy burden of disease worldwide [28]. Exposure to SHS during pregnancy was common in pregnant women population.

Our results are in line with prior studies $[15,29]$ that women's higher educational attainment was independent protective factor for reducing SHS exposure. Education is one aspect of the basic drivers of human behaviour that can promote healthy behavior and keep individual away from harmful exposure [30]. Generally, pregnant women who were more educated had more active enhance the awareness of tobacco, reduce exposure. Meanwhile, the availability of various medical and economic resources may depend on educational attainment. Thus, educational attainment can be regarded as a vital determinant of SHS exposure. In our study, we also confirmed those participants were unemployed had greater risk for SHS exposure. Employment and education were strongly associated, both has impacts on household income and social conditions of resources. Previous studies had showed unemployment or manual working status were predictors of maternal SHS exposure during pregnancy [24, 31, 32]. Participants who being more educated were more likely to have steady job, that increased the likelihood of engaging health behavior and active away from harmful exposure [33]. Conversely, those unemployed women have limited health education resources, weak awareness of the harms of exposure to SHS and self-perception of relatively low status within the family, increasing the possibility of being SHS exposure. Interestingly, we found lower person income per month might be considered as protective factor for SES exposure, it might reflect a shift in the association between income and SHS exposure. These observations supported that of previous studies conducted by Receea et al and Mahmoodabad et al [2, 19], but contradicted by the evidences from Yang and colleague [27]. Nevertheless, as far as we are concerned, after adjustment for related background variables, there was no significant association between income and SHS exposure. The reason behind that whether the highly income greater the risk of SHS exposure among pregnant women still undetermined, and further research will be needed to explain the phenomenon. The significant results in our findings indicated that those women be exposure to SHS were often with lower education and unemployed.

Notably, age has influence on the relationship between lower level of educational attainment and unstable marriage status. Those women of above characteristics were related to higher risk of SHS 
exposure with age. Previous studies have indicated, younger age of women were more likely to be exposure to SHS [17, 34-36], but in the study of St Helen et al, indicated that women aged over 35 years had higher level of UC (urinary cotinine) due to SHS exposure in home [37]. Moreover, number of evidences showed that the older age of spouse/partner was a risk risk for SES exposure [19]. Link and Phelan explained that SES is fundamental causes of disease due to the closely associated with access to important resources, affect multiple disease outcomes through multiple mechanisms [38]. However, their capacity to use resources to gain a health advantage is more and more weak in these population located in relatively low level of SES with age. In particular, women were expected to obedient to their spouse in family of traditional Chinese culture background. It could be speculated that pregnant women of lower level of educational attainment and unstable marriage were less likely to change smoking behavior of their spouse/partner, exposure to SHS might more frequent occur.

Avoiding SHS exposure during pregnancy is an important health priorities for healthcare professionals and policy-makers. However, researchers stated that it was still hard to eliminate SHS exposure during pregnancy in LMICs, China included. First, the awareness of harmful outcomes attributed by SHS exposure was lower in that LMICs [39]. Second, the pregnant women may not argue with male due to the existence of male-dominated ideology, even though they have already realized the risk of SHS exposure [40]. Importantly, despite the smoker tried to avoid directly contact with pregnant women, SHS was much difficult be avoided. One important reason was that the hidden demon called as "third-hand smoke (THS)" still staying in environment especially skin and clothes, which posed new threat to pregnant women, nonetheless, the risk of THS is scanty known by pregnant women and their family member [41]. In addition, family's consensus on smoking ban may be an effective strategy [23], as in the pregnancy women are well protected in family, particularly their spouse/partner value their advice. In a word, it is imperative for both pregnant women and their spouse/partner to be included in interventions for tobacco control and ongoing implementation of preconception and pregnancy health education.

Some limitation of this study should be recognized. First, the status of exposure to SHS was determined using participants' self-reported, this might have led to an recalling bias of the measurement effect of SHS, to some extent. However, prior investigations found measuring SHS exposure by self-reported still a satisfied and acceptable approach of SHS exposure and widely used in increasing number of studies [42]. The cross-sectional study had practical limitations in causal inference. The longitudinal and qualitative research are needed to help identify the association between SHS exposure and SES. In addition, spouse/partner's SES also partially explained the association between SHS exposure and social status [19]. However, no significant differences were observed between these SES variables of spouse/partner in terms of group comparison analysis. Lastly, we only taken spouse/partner as an account for sources of SHS exposure. Whereas, we considered that the contribution of other sources of SHS such as workplace and restaurant was negligible, given that pregnant women general spend most of their time with spouse/partner during pregnancy.

In summary, the risk perceptions and communication were related with SES [43], which could suggest that SES may have practical applied to smoking cessation implementation. Pregnant women are an key

Page 13/19 
sub-population that should be implement tobacco control efforts for their spouse/partner because both cigarettes and smokeless tobacco pose serious threat to mother and fetus. This paper results indicated that, to a certain extent, a lower level of SES leading to a higher likelihood of the SHS exposure. Intensified spouse's behavior change their smoking behavior and protect the health of pregnant women

\section{Conclusion}

In conclusion, our findings showed the SHS exposure still a challenge for pregnant women health. Provide preventative strategies for passive smoking and focus on such vulnerable population of low level of SES and pregnant woman of advanced age when targeting future smoking cessation interventions among them as well as among others who plan to become pregnant.

\section{Abbreviations}

SHS: Second hand smoke;SES: Socioeconomic status

\section{Declarations}

\section{Acknowledgements}

This is a short text to acknowledge the contributions of specific colleagues, institutions, or agencies that aided the efforts of the authors.

\section{Funding}

This study was financially supported by the National Natural Science Foundation of China (81701356), Major Scientific and Technological Projects for the Collaborative Prevention and Control of Birth Defects in Hunan Province (2019SK1015), the science and technology programs of Changsha city (kq1801084) and technology projects of Administration of Traditional Chinese Medicine (201918).

\section{Availability of data and materials}

The data from which this manuscript was developed are available on request from the corresponding author.

\section{Authors' Contributions}

Wensu Zhou, Baohua Zhen, Yunhan Yu, Xidi Zhu, Zhao Hu: Collect data; Wensu Zhou, Xidi Zhu, Zhao Hu: Conceptualization; Wensu Zhou, Xiyue Xiong: Data curation, Writing, Original draft preparation, Methodology, Software, Reviewing; Wensu Zhou, Xidi Zhu, Zhao Hu, Li Shaojie: Visualization, Investigation. Xidi Zhu, Zhao Hu, Li Shaojie, , Xu Huilan, Xiyue Xiong: Supervision. 
The authors declare that they have no competing interests.

Consent to publish

The participants gave consent for the findings of the study to be published.

Ethics approval and consent to participate

The study has been approved by the Ethics Committee of the Xiangya school of Public Health, Central South University on 15, July, 2019 (XYGW-2019-056). Written informed consent was obtained from participants before interview. The authors confirmed that all methods were carried out in accordance with relevant guidelines and regulations

\section{References}

1. Organization WH: Gender, Health, Tobacco and Equity, 2011. 2011.

2. Reece S, Morgan C, Parascandola M, Siddiqi K: Secondhand smoke exposure during pregnancy: a cross-sectional analysis of data from Demographic and Health Survey from $\mathbf{3 0}$ low-income and middleincome countries. Tob Control 2019, 28(4):420-426.

3. Chomba E, Tshefu A, Onyamboko M, Kaseba-Sata C, Moore J, McClure EM, Moss N, Goco N, Bloch M, Goldenberg RL: Tobacco use and secondhand smoke exposure during pregnancy in two African countries: Zambia and the Democratic Republic of the Congo. Acta Obstet Gynecol Scand 2010, 89(4):531-539.

4. Zhang L, Hsia J, Tu X, Xia Y, Zhang L, Bi Z, Liu H, Li X, Stanton B: Exposure to secondhand tobacco smoke and interventions among pregnant women in China: a systematic review. Prev Chronic Dis 2015, 12:E35.

5. Golan R, Kloog I, Almog R, Gesser-Edelsburg A, Negev M, Jolles M, Shalev V, Eisenberg VH, Koren G, Abu Ahmad W et al: Environmental exposures and fetal growth: the Haifa pregnancy cohort study. BMC Public Health 2018, 18(1):132.

6. Sun W, Huang X, Wu H, Zhang CJP, Yin Z, Fan Q, Wang H, Jayavanth P, Akinwunmi B, Wu Y et al: Maternal tobacco exposure and health-related quality of life during pregnancy: a national-based study of pregnant women in China. Health Qual Life Outcomes 2021, 19(1):152.

7. Eiden RD, Molnar DS, Leonard KE, Colder CR, Homish GG, Maiorana N, Schuetze P, Connors GJ: Sources and frequency of secondhand smoke exposure during pregnancy. Nicotine Tob Res 2011, 13(8):653-660.

8. WHO report on the global tobacco epidemic, 2009: Implementing smoke-free environments.

Geneva, 2009 [http://www.who.int/tobacco/mpower/2009/en/index.html] 
9. Windhama GC, Eatona A, Hopkins B: Evidence for an association between environmental tobacco smoke exposure and birthweight: a metaanalysis and new data. Paediatric and Perinatal Epidemiology 1999, 13:35-57.

10. Huang J, Wen G, Yang W, Yao Z, Wu C, Ye X: The association between second-hand smoke exposure and depressive symptoms among pregnant women. Psychiatry Res 2017, 256:469-474.

11. Farah MJ: Socioeconomic status and the brain: prospects for neuroscience-informed policy. Nat Rev Neurosci 2018, 19(7):428-438.

12. Stanford-Moore G, Bradshaw PT, Weissler MC, Zevallos JP, Brennan P, Anantharaman D, AbediArdekani B, Olshan AF: Interaction between known risk factors for head and neck cancer and socioeconomic status: the Carolina Head and Neck Cancer Study. Cancer Causes Control 2018, 29(9):863-873.

13. Smedberg J, Lupattelli A, Mårdby A-C, Nordeng H: Characteristics of women who continue smoking during pregnancy: a cross-sectional study of pregnant women and new mothers in 15 European countries. BMC Pregnancy and Childbirth 2014, 14:213-229.

14. Mishra GA, Kulkarni SV, Gupta SD, Shastri SS: Smokeless tobacco use in Urban Indian women: Prevalence and predictors. Indian journal of medical and paediatric oncology : official journal of Indian Society of Medical \& Paediatric Oncology 2015, 36(3):176-182.

15. Madureira J, Camelo A, Silva Al, Reis AT, Esteves F, Ribeiro Al, Teixeira JP, Costa C: The importance of socioeconomic position in smoking, cessation and environmental tobacco smoke exposure during pregnancy. Sci Rep 2020, 10(1):15584.

16. Cai L, Wu X, Goyal A, Han Y, Cui W, Xiao X, He J, Zhao K, Song Y, Jiao F: Patterns and socioeconomic influences of tobacco exposure in tobacco cultivating rural areas of Yunnan Province, China. BMC Public Health 2012, 12(1):842.

17. Hikita N, Haruna M, Matsuzaki M, Sasagawa E, Murata M, Oidovsuren O, Yura A: Prevalence and risk factors of secondhand smoke (SHS) exposure among pregnant women in Mongolia. Sci Rep 2017, 7(1):16426.

18. Rocheleau CM, Bertke SJ, Lawson CC, Romitti PA, Desrosiers TA, Agopian AJ, Bell E, Gilboa SM, National Birth Defects Prevention S: Factors associated with employment status before and during pregnancy: Implications for studies of pregnancy outcomes. Am J Ind Med 2017, 60(4):329-341.

19. Mahmoodabad SSM, Karimiankakolaki Z, Kazemi A, Mohammadi NK, Fallahzadeh H: Exposure to secondhand smoke in Iranian pregnant women at home and the related factors. Tob Prev Cessat 2019, $5: 7$. 
20. Kiecolt-Glaser JK, Newton TL: Marriage and health: his and hers. Psychological bulletin 2001, 127(4):472-503.

21. Ngobese SP, Egbe CO, Londani M, Ayo-Yusuf OA: Non-Smoker's Exposure to Second-Hand Smoke in South Africa during 2017. Int J Environ Res Public Health 2020, 17(21).

22. Mistry R, Dasika A: Antenatal Tobacco Use and Secondhand Smoke Exposure in the Home in India. Nicotine Tob Res 2018, 20(2):258-261.

23. Chen J, Li X, Fang P: Influence of family resources on secondhand smoking in pregnant women: a cross-sectional study in the border and minority urban areas of Northwest China. BMC Pregnancy Childbirth 2020, 20(1):642.

24. Yaya S, Uthman OA, Adjiwanou V, Bishwajit G: Exposure to tobacco use in pregnancy and its determinants among sub-Saharan Africa women: analysis of pooled cross-sectional surveys. $J$ Matern Fetal Neonatal Med 2020, 33(9):1517-1525.

25. Prus SG: Age, SES, and health: a population level analysis of health inequalities over the lifecourse. Sociol Health IIIn 2007, 29(2):275-296.

26. Wang M, Luo X, Xu S, Liu W, Ding F, Zhang X, Wang L, Liu J, Hu J, Wang W: Trends in smoking prevalence and implication for chronic diseases in China: serial national cross-sectional surveys from 2003 to 2013. The Lancet Respiratory medicine 2019, 7(1):35-45.

27. Yang L, Tong EK, Mao Z, Hu TW: Exposure to secondhand smoke and associated factors among nonsmoking pregnant women with smoking husbands in Sichuan province, China. Acta Obstet Gynecol Scand 2010, 89(4):549-557.

28. Carreras G, Lugo A, Gallus S, Cortini B, Fernandez E, Lopez MJ, Soriano JB, Lopez-Nicolas A, Semple $\mathrm{S}$, Gorini $\mathrm{G}$ et al: Burden of disease attributable to second-hand smoke exposure: A systematic review. Prev Med 2019, 129:105833.

29. Hawkins SS, Dacey C, Gennaro S, Keshinover T, Gross S, Gibeau A, Lulloff A, Aldous KM: Secondhand smoke exposure among nonsmoking pregnant women in New York City. Nicotine Tob Res 2014, 16(8):1079-1084.

30. Stormacq C, Van den Broucke S, Wosinski J: Does health literacy mediate the relationship between socioeconomic status and health disparities? Integrative review. Health Promot Int 2019, 34(5):e1-e17.

31. de Wolff MG, Backhausen MG, Iversen ML, Bendix JM, Rom AL, Hegaard HK: Prevalence and predictors of maternal smoking prior to and during pregnancy in a regional Danish population: a crosssectional study. Reprod Health 2019, 16(1):82. 
32. Al-Sahab B, Saqib M, Hauser G, Tamim H: Prevalence of smoking during pregnancy and associated risk factors among Canadian women: a national survey. BMC Pregnancy Childbirth 2010, 10:24.

33. Xu X, Rao Y, Wang L, Liu S, Guo JJ, Sharma M, Zhao Y: Smoking in pregnancy: a cross-sectional study in China. Tob Induc Dis 2017, 15:35.

34. Polanska K, Krol A, Kaluzny P, Ligocka D, Mikolajewska K, Shaheen S, Walton R, Hanke W: Estimation of Saliva Cotinine Cut-Off Points for Active and Passive Smoking during Pregnancy-Polish Mother and Child Cohort (REPRO_PL). Int J Environ Res Public Health 2016, 13(12).

35. Norsa'adah B, saliNah O: The Effect of Second-Hand Smoke Exposure during Pregnancy on the Newborn Weight in Malaysia Malays J Med Sci 2014, 21(2):44-53.

36. Aurrekoetxea JJ, Murcia M, Rebagliato M, Fernandez-Somoano A, Castilla AM, Guxens M, Lopez MJ, Lertxundi A, Espada M, Tardon A et al: Factors associated with second-hand smoke exposure in nonsmoking pregnant women in Spain: self-reported exposure and urinary cotinine levels. Sci Total Environ 2014, 470-471:1189-1196.

37. St Helen G, Bernert JT, Hall DB, Sosnoff CS, Xia Y, Balmes JR, Vena JE, Wang JS, Holland NT, Naeher LP: Exposure to secondhand smoke outside of a bar and a restaurant and tobacco exposure biomarkers in nonsmokers. Environ Health Perspect 2012, 120(7):1010-1016.

38. Link BG, Phelan J: Social conditions as fundamental causes of disease. J Health Soc Behav 1995, Spec No:80-94.

39. Yousuf $H$, Hofstra M, Tijssen J, Leenen B, Lindemans JW, van Rossum A, Narula J, Hofstra L: Estimated Worldwide Mortality Attributed to Secondhand Tobacco Smoke Exposure, 1990-2016. JAMA Netw Open 2020, 3(3):e201177.

40. Passey ME, Longman JM, Robinson J, Wiggers J, Jones LL: Smoke-free homes: what are the barriers, motivators and enablers? A qualitative systematic review and thematic synthesis. BMJ Open 2016, 6(3): $\mathrm{e} 010260$.

41. Lidon-Moyano C, Fu M, Perez-Ortuno R, Ballbe M, Garcia E, Martin-Sanchez JC, Pascual JA, Fernandez E, Martinez-Sanchez JM: Third-hand exposure at homes: Assessment using salivary cotinine. Environ Res 2021, 196:110393.

42. Lee BE, Hong YC, Park H, Ha M, Kim JH, Chang N, Roh YM, Kim BN, Kim Y, Oh SY et al: Secondhand smoke exposure during pregnancy and infantile neurodevelopment. Environ Res 2011, 111(4):539-544.

43. Wagner GA, Sanchez ZM, Fidalgo TM, Caetano SC, Carliner H, Martins SS: Sociodemographic factors associated with smoking risk perception in adolescents in Sao Paulo, Brazil. Braz J Psychiatry 2019, 41(6):546-549. 
Figures

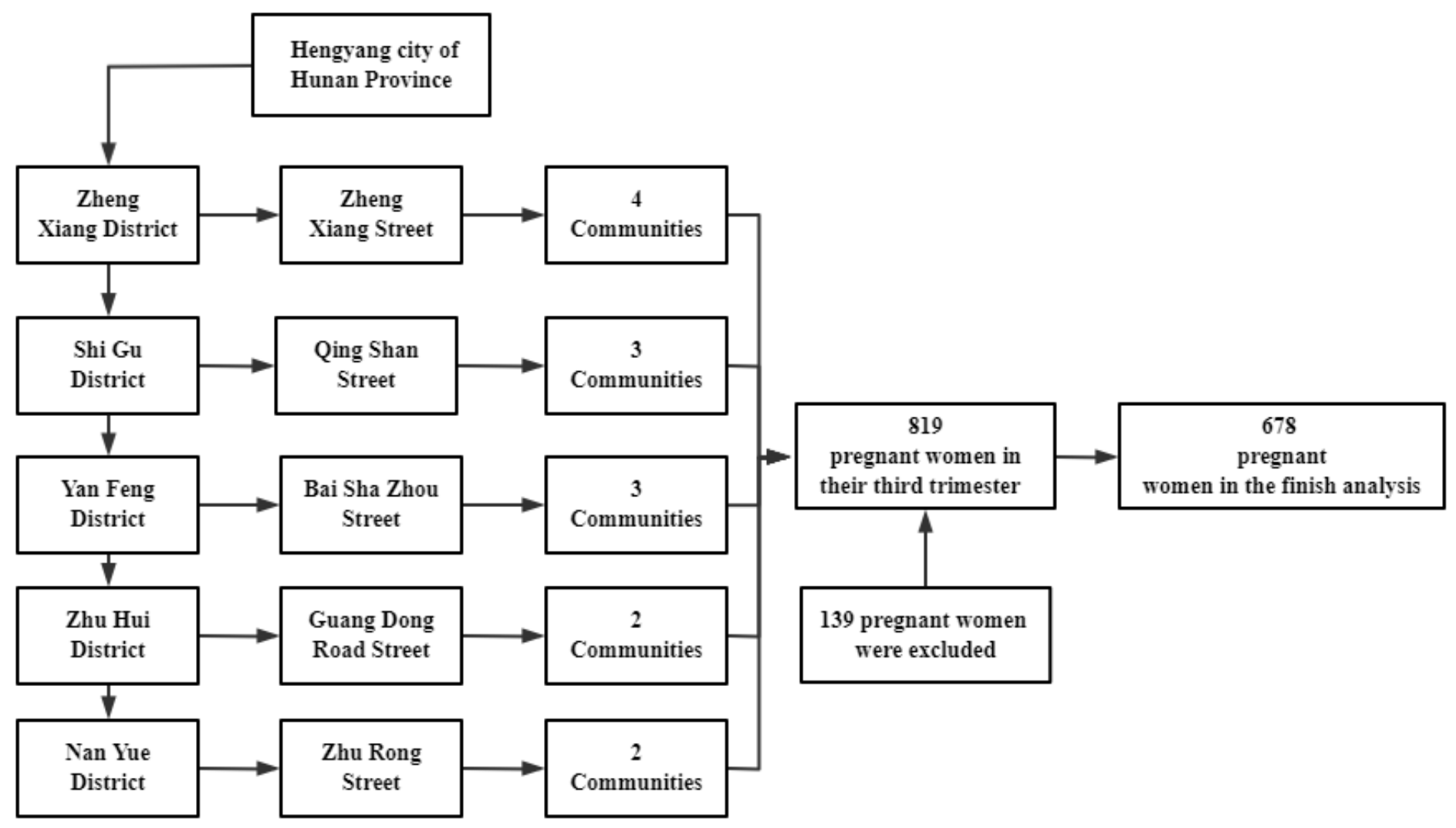

\section{Figure 1}

The study strategy of the study 